\title{
Immunocytochemical profiles of inferior colliculus neurons in the rat and their changes with aging
}

\section{Ladislav Ouda* and Josef Syka}

Institute of Experimental Medicine, Academy of Sciences of the Czech Republic, Prague, Czech Republic

\section{Edited by:}

Manuel S. Malmierca, University of Salamanca, Spain

Reviewed by:

Miguel A. Merchán, Universidad de Salamanca, Spain

Robert D. Frisina, University of

South Florida, USA

*Correspondence:

Ladislav Ouda, Institute of

Experimental Medicine, Academy

of Sciences of the Czech Republic

Vídeňská 1083, 14220 Prague,

Czech Republic.

e-mail: ouda@biomed.cas.cz
The inferior colliculus (IC) plays a strategic role in the central auditory system in relaying and processing acoustical information, and therefore its age-related changes may significantly influence the quality of the auditory function. A very complex processing of acoustical stimuli occurs in the IC, as supported also by the fact that the rat IC contains more neurons than all other subcortical auditory structures combined. GABAergic neurons, which predominantly co-express parvalbumin (PV), are present in the central nucleus of the IC in large numbers and to a lesser extent in the dorsal and external/lateral cortices of the IC. On the other hand, calbindin (CB) and calretinin (CR) are prevalent in the dorsal and external cortices of the IC, with only a few positive neurons in the central nucleus. The relationship between $\mathrm{CB}$ and $\mathrm{CR}$ expression in the $\mathrm{IC}$ and any neurotransmitter system has not yet been well established, but the distribution and morphology of the immunoreactive neurons suggest that they are at least partially non-GABAergic cells. The expression of glutamate decarboxylase (GAD) (a key enzyme for GABA synthesis) and calcium binding proteins (CBPs) in the IC of rats undergoes pronounced changes with aging that involve mostly a decline in protein expression and a decline in the number of immunoreactive neurons. Similar age-related changes in GAD, CB, and CR expression are present in the IC of two rat strains with differently preserved inner ear function up to late senescence (Long-Evans and Fischer 344), which suggests that these changes do not depend exclusively on peripheral deafferentation but are, at least partially, of central origin. These changes may be associated with the age-related deterioration in the processing of the temporal parameters of acoustical stimuli, which is not correlated with hearing threshold shifts, and therefore may contribute to central presbycusis.

Keywords: inferior colliculus, GABA, parvalbumin, calbindin, calretinin, aging, rat

\section{INTRODUCTION}

The inferior colliculus (IC) occupies a strategic position in the central auditory system. Almost all of the ascending projections from the lower auditory regions (cochlear nuclei, superior olivary complex, and lemniscus lateralis) converge in the central nucleus of the IC, thus making this structure a converging hub of the ascending as well as the descending auditory pathways of the auditory system (Beyerl, 1978; Druga and Syka, 1984a,b; Pollak and Casseday, 1986; Oliver and Huerta, 1992; Druga et al., 1997; Casseday et al., 2002). Simultaneously, the IC operates as a relay structure to the medial geniculate body (MGB) and subsequently to the auditory cortex.

With respect to its internal composition, the rat IC is subdivided into three major parts, the central nucleus and the dorsal and external (lateral) cortices. This division is visible in most histological and immunohistochemical stainings (Morest and Oliver, 1984; Faye-Lund and Osen, 1985; Malmierca et al., 1993), (Figure 1). In addition, the separation of the ventrolateral nucleus from the external cortex of the IC was proposed, based on homology with the ventrolateral nucleus in the cat (Loftus et al., 2008). The central nucleus of the IC (CIC) represents a part of the primary auditory pathway with a preserved tonotopy, sending primary ascending projections to the ventral subdivision of the MGB and receiving only weak descending projections from the telencephalon (Diamond et al., 1969; Druga and Syka, 1984a,b; Kudo and Nakamura, 1988; Schneiderman et al., 1988). In contrast, the dorsal (DIC) and external (EIC) cortices are more influenced by ascending monoaural pathways and by descending projections from layer $\mathrm{V}$ and, to lesser extent, from layer VI of the auditory and non-auditory cortical fields (Druga and Syka, 1984a,b; Saldana et al., 1996; Druga et al., 1997; Winer et al., 1998; Schofield, 2009). The external cortex of the IC possesses strong connections with non-auditory structures including the colliculus superior, substantia nigra, periaquaductal gray, and somatosensory cortex (Syka and Straschill, 1970; Syka and RadilWeiss, 1971; Aitkin et al., 1978; Druga and Syka, 1984c; Tokunaga et al., 1984; Zhou and Shore, 2006).

Almost the entire GABAergic dorsal nucleus of the lateral lemniscus (Zhang et al., 1998) and the superior paraolivary nucleus (Kulesza and Berrebi, 2000; Saldaña et al., 2009) as well as a substantial portion of neurons from the ventral nucleus of the lateral lemniscus (Riquelme et al., 2001) send ascending inhibitory projections to the neurons of the IC (ipsi- and contralaterally), while excitatory ascending projections originate 


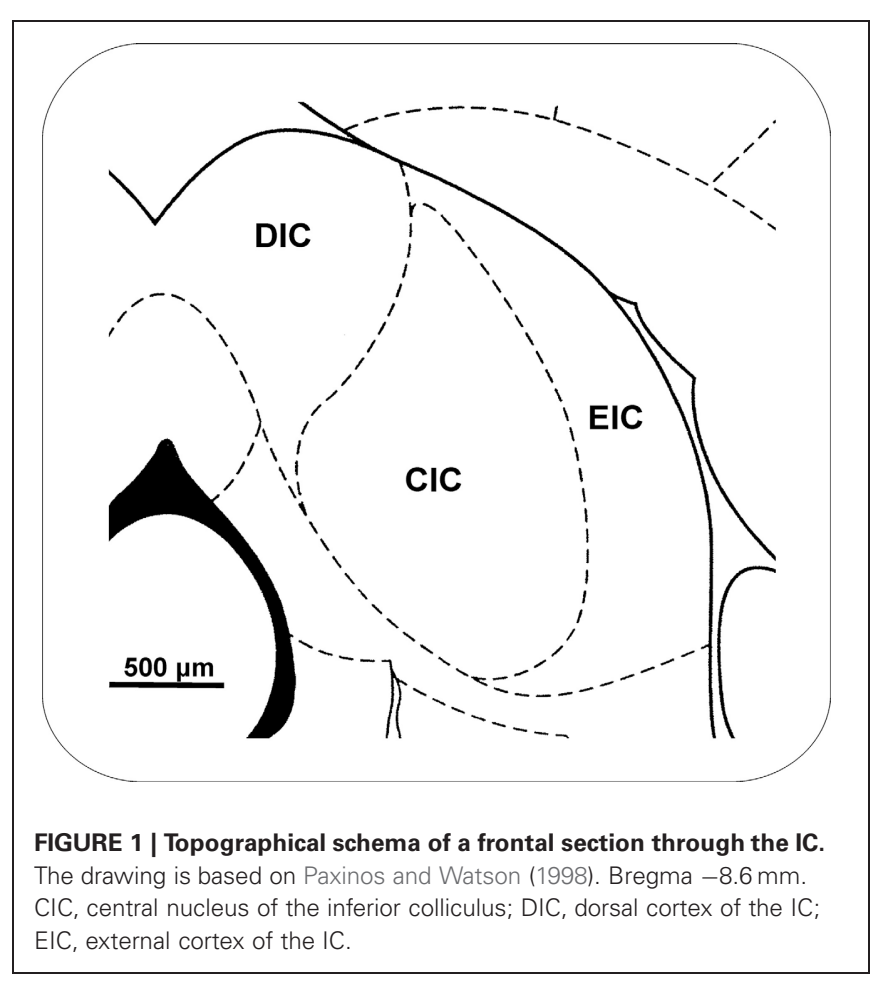

predominantly from the lateral and medial superior olive and cochlear nuclei (Semple and Aitkin, 1980; Frisina et al., 1998; Malmierca et al., 1998; Riquelme et al., 2001; Davis, 2002; Malmierca et al., 2005). In addition, the contralateral IC is also a source of mostly inhibitory projections to the IC (GonzálezHernández et al., 1996). GABAergic perisomatic terminals are more prevalent on non-GABAergic neurons in the IC (Merchán et al., 2005).

The strong representation of GABA terminals as well as the high proportion of GABAergic cells in this structure in the rat suggests the presence of strong inhibitory processes in the IC (Gerken, 1996; Batra and Fitzpatrick, 2002; Merchán et al., 2005; Pollak et al., 2011). The GABAergic inhibitory system in the IC serves to modulate the spectral and temporal properties of IC responses with the aim of sharpening the responses to rapid complex sounds (Le Beau et al., 1996; Palombi and Caspary, 1996; Frisina, 2001; Walton et al., 2002).

Besides GABAergic inhibition, also present are significantly weaker glycinergic inhibitory projections onto the IC neurons from various sources (Saint Marie et al., 1989; Saint Marie and Baker, 1990). The presence of glycinergic neurons in the IC is controversial, since Merchán et al. (2005) reported no glycinergic neurons throughout the IC, while Fredrich et al. (2009) observed glycine immunoreactivity in about $1 / 6$ of CIC neurons, however, always in colocalization with GABA. GABAergic puncta were observed both in the neurophil and in the contacts with neuronal somas, whereas very few glycinergic terminals contacted the somata (Merchán et al., 2005).

Auditory function in mammals, including humans, is known to be significantly affected by aging, ultimately resulting in presbycusis with alterations occurring both in the inner ear and in the central auditory system (Syka, 2002; Frisina and Rajan, 2005; Gates and Mills, 2005; Ohlemiller and Frisina, 2008; Frisina, 2009, 2010; Gordon-Salant et al., 2010). The central component of presbycusis is thought to be significantly associated with age-related alterations in the processing of the temporal parameters of complex acoustical stimuli within the central auditory system, especially the IC and auditory cortex (Strouse et al., 1998; Walton et al., 1998, 2002; Frisina and Walton, 2006; Walton et al., 2008; Walton, 2010; Suta et al., 2011). In the human population, a loss of speech understanding with aging constitutes an important health and social impairment (Frisina and Frisina, 1997; Mazelová et al., 2003; Gates and Mills, 2005; Gordon-Salant et al., 2007).

The significance of inhibition for the processing of information occurring in the IC is difficult to overemphasize, as reviewed in detail, e.g., by Pollak et al. (2011). Altered inhibition within the IC of animals may have a severe impact on survival in the wild, since it impairs their ability to refine the localization of a sound source in the environment (Litovsky and Delgutte, 2002; Pecka et al., 2007). In addition, under experimental conditions, the selectivity for features of incoming signals is significantly reduced or eliminated in the majority of IC cells when inhibition is blocked (Casseday et al., 2000; Malmierca et al., 2003; Nataraj and Wenstrup, 2005; Sanchez et al., 2007). Since GABAmediated inhibition in the IC and auditory cortex is strongly involved in the temporal processing of complex acoustical stimuli, including human language (Walton et al., 1997, 1998; Strouse et al., 1998; Krishna and Semple, 2000; Walton et al., 2002; Suta et al., 2003; Simon et al., 2004), a functional decline in GABA-mediated inhibition may significantly contribute to a deterioration of hearing with aging, i.e., the central component of presbycusis.

In the last few years, we have evaluated age-related changes comprising mostly a decline in the expression of glutamate decarboxylase (GAD) and calcium binding proteins (CBPs) in the higher levels of the rat auditory pathway, including the IC and auditory cortex (Ouda et al., 2008; Burianova et al., 2009; Ouda et al., 2012b). An age-related decline in GABA levels in the IC was previously reported by other authors (Caspary et al., 1990; Gutiérrez et al., 1994; Raza et al., 1994; Caspary et al., 1995). A decreased number of GABA or GAD immunoreactive neurons was also documented in other parts of the rat brain, such as in the hippocampus (Shi et al., 2004; Stanley and Shetty, 2004; Ling et al., 2005), while no significant reduction was found in the sensorimotor or parietal cortex (Poe et al., 2001; Ling et al., 2005; Shi et al., 2006). Age-related changes in the levels of the CBPs in the auditory pathway were also evaluated in the cochlear nuclei and IC of mice. In addition, the reported changes were strain-dependant for all three proteins in the cochlear nuclei (Idrizbegovic et al., 2001, 2004) and for calretinin (CR) in the IC (Zettel et al., 1997).

In the following text, we first discuss in several chapters the quantitative data, the neuronal types and the distribution of particular immunoreactive neuronal populations in the IC of young adult animals. In the second half, we summarize the observed immunohistochemical age-related changes in the IC and their link to electrophysiological and behavioral findings. 


\section{HISTOCHEMICAL PROFILES OF THE INFERIOR COLLICULUS IN YOUNG RATS \\ TOTAL NUMBER OF NEURONS IN THE IC}

The number of neurons in the IC, based on Nissl stained sections, in comparison with other central auditory structures in the rat has been reported in two recent papers (Kulesza et al., 2002; Ouda et al., 2012a). The rat IC contains about 350,000 neurons, with more than 200,000 neurons in the central nucleus alone, about 80,000 in the EIC and 45,000 in the DIC. This represents several times more neurons than in all lower auditory regions combined (cochlear nuclei-30,000 superior olivary complex$16,000-18,000$ and lemniscus lateralis-15,000-18,000). In contrast to the IC, the next structure in the auditory pathway, the MGB, contains only about $60,000-70,000$ neurons in the rat (with 40,000-45,000 in the ventral division of the MGB), which represents a large difference in comparison to the IC.

In this respect, the position of the MGB may be specific to some degree in the rodent, while the number of neurons in the MGB was reported to be significantly species-dependent, with markedly higher numbers in carnivores and especially in humans (Dorph-Petersen et al., 2009; Najdzion et al., 2011). On the other hand, the absolute number of neurons in the IC of rats and humans is suprisingly comparable, 350,000 vs cca 400,000 neurons (Sharma et al., 2009-a 5-month-old baby that died of postoperative complications after cardiac surgery). In addition, the total number of neurons in the rat auditory cortex is probably roughly the same as in the rat $\mathrm{IC}(\mathrm{Te} 1, \mathrm{Te} 2, \mathrm{Te} 3$-about 600,000 neurons; Ouda et al., 2012a), while, e.g., in primates the divergence of the ascending auditory pathway rapidly increases further through the MGB to the auditory cortical areas. For example, the total number of neurons in the whole human neocortex is almost three orders of magnitude larger than in the whole rat neocortex (Pakkenberg and Gundersen, 1997; Herculano-Houzel and Lent, 2005). These findings strongly support the prominent role of the IC in the rodent central auditory system and suggest that the role of the MGB in rodents may be somewhat different than in other mammalian species.

\section{GLUTAMATE DECARBOXYLASE}

GABA is synthesized by the decarboxylation of glutamate, and the reaction is catalyzed by the key rate-limiting enzyme GAD. In the mammalian brain, two GAD isoforms of 65 and $67 \mathrm{kDa}$ molecular weight (GAD 65 and GAD 67) are present (Erlander et al., 1991). Most GABA-expressing neurons contain both isoforms, and therefore GAD immunostaining is often used to identify GABAergic neurons (Erlander and Tobin, 1991; Feldblum et al., 1993; Esclapez et al., 1994; Hendrickson et al., 1994). In the rat, GAD65- and 67-immunoreactive(-ir) neurons are distributed throughout all three subdivisions of the IC (Merchán et al., 2005; Burianova et al., 2009) (Figures 2A, 3).

In the CIC of rats, GAD-ir cell bodies of variable sizes are present, relatively homogenously distributed, with a variation in the intensity of immunostaining (Merchán et al., 2005; Burianova et al., 2009). With respect to morphology, the GAD-ir neurons are thought to correspond mostly to the less-flat neurons in the CIC (Malmierca et al., 1993, 1995a), which are homologous to stellate neurons in the CIC of the cat (Oliver, 1984; Oliver et al.,
1994). Merchán et al. (2005) proposed that the majority of lessflat neurons are GABAergic, while the majority of flat neurons are excitatory cells (disc-shaped cells in the cat). GABAergic neurons were also reported to be larger on average in their somas when compared to non-GABA neurons in the IC, especially in the CIC (Merchán et al., 2005; Fredrich et al., 2009). In our experiments (Burianova et al., 2009), we did not quantify the size of GAD-ir neurons in comparison to immunonegative ones; however, in terms of morphology, the GAD-ir cells observed in the CIC belonged mostly to the less-flat neurons, with polygonal or oval shapes. In addition, we did not observe any distribution that resembled the location and orientation of the fibrodendritic laminae, which were described to comprise flat cells in the rat (Malmierca et al., 1993) or disc-shaped cells in cat (Morest and Oliver, 1984; Oliver and Morest, 1984).

In the external and dorsal cortices, the identification of morphological types is more complicated. The majority of GAD-ir neurons in the external cortex of the rat IC (EIC) are either large fusiform cells or smaller oval neurons, in both the second and third layers of the EIC. The GAD-ir neurons in the EIC resemble some types described with Rio-Hortega Golgi staining in the rat IC by Malmierca et al. (2011). Especially the large fusiform-like neurons, stained in our sections for GAD (Burianova et al., 2009), might correspond to the second major neuronal type in the EIC, called bitufted neurons with spindle, fusiform somas. In addition, Malmierca et al. (2011) also observed in the second layer of the rat EIC cluster-like groups of small neurons that may correspond to the modules described in detail by Chernock et al. (2004) and found in our own experiments as clusters of GAD-ir (and PV-ir) neurons (Ouda et al., 2008; Burianova et al., 2009). In the rat DIC, the situation is even more complex due to the large heterogeneity of neuronal shapes (Malmierca et al., 2011), which makes direct identification from immunostained sections practically impossible. In our GAD-staining, lower numbers, in comparison to the EIC and CIC, of predominantly small-sized immunoreactive neurons with a homogenous distribution were present in the rat DIC (Burianova et al., 2009).

The clusters of small neurons and intensely stained neuropil in the second layer of the rat EIC described by Chernock et al. (2004) are clearly visible in most sections to the naked eye (Chernock et al., 2004; Burianova et al., 2009). In addition to GAD, the clusters are immunopositive for NADPH-diaphorase and parvalbumin $(\mathrm{PV})$, whereas they are immunonegative for glycine, $\mathrm{CB}$, choline acetyltransferase, and SMI-32. These clusters or modules are absent in the mouse, squirrel, cat, bat, and macaque monkey, and so far they have been found only in rats and were suggested to possibly participate in the animal's spatial orientation (Chernock et al., 2004).

As already mentioned, the GABAergic neurons represent a substantial part of all neurons in the IC. In rats, the portion of inhibitory neurons in the IC seems to be larger than in the cat or bat; specifically; the CIC of the rat contains more than $30 \%$ of GABAergic neurons, whereas in the same structure of the cat or the bat they represent approximately 20\% (Oliver et al., 1994; Winer et al., 1995; Merchán et al., 2005; Fredrich et al., 2009). The rat DIC and EIC are reported to contain about $20-25 \%$ of GABAergic neurons, while the data from other mammalian 


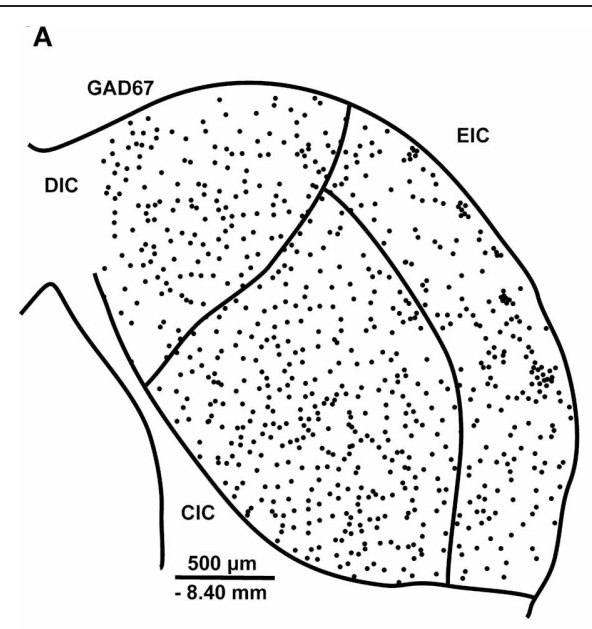

C

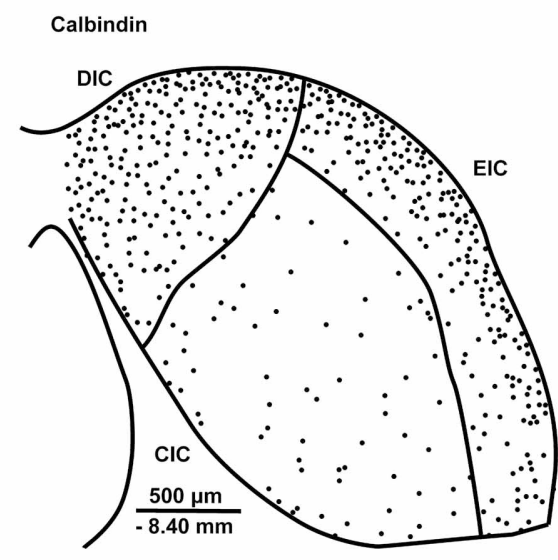

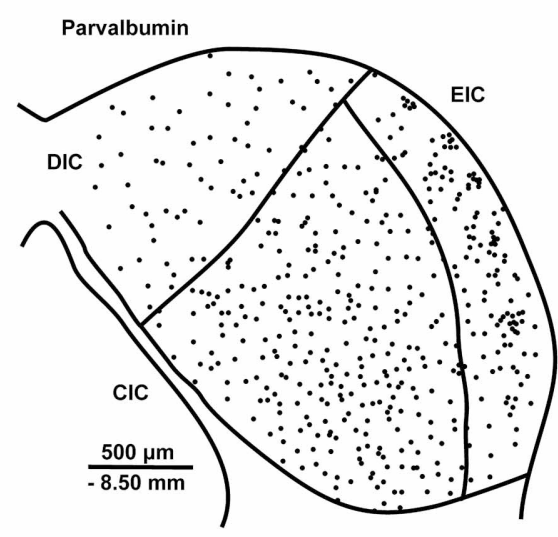

D

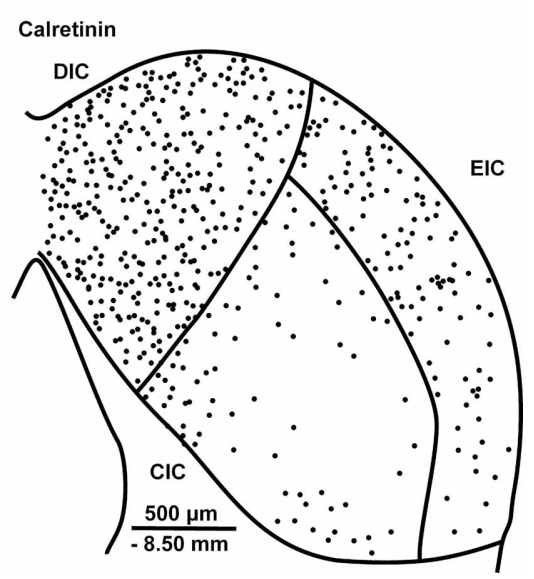

FIGURE 2 | Schematic illustration of the distribution of glutamate decarboxylase. GAD67 (A), parvalbumin (B), calbindin (C) and calretinin (D) immunoreactive neurons in a section containing all three major subdivisions of the $\mathrm{IC}$, the central nucleus and the dorsal and external cortices, in young adult Long-Evans rats. $\mathrm{CIC}$, central nucleus of the inferior colliculus; DIC, dorsal cortex of the inferior colliculus; EIC, external cortex of the inferior colliculus; GAD67, glutamate decarboxylase, isoform 67; PV, parvalbumin; CB, calbindin; CR, calretinin. The distance from bregma and scale bars are provided in each panel. The displayed schema is based on the distribution of GAD67-, PV-, CB-, and CR-ir neurons observed in our previous publications (Ouda et al., 2008; Burianova et al., 2009; Ouda et al., 2012b). species are not known (Merchán et al., 2005). In addition to this, the GABAergic projection from the IC to the MGB has been reported to be more prominent in the rat than in some nonrodent species (Peruzzi et al., 1997; Ito et al., 2009). The reason for the difference from the known results in other mammalian orders is not clear. However, the next structure in the rat ascending auditory pathway, the MGB, contains almost no inhibitory neurons in the rat in contrast to other mammals. In the rat MGB, GABAergic neurons represent less than $1 \%$ of cells, while they form a significant portion $(25 \%)$ of all neurons in the cat or primate MGB (Winer and Larue, 1996). Therefore, the only inhibition in the rat MGB is of extrinsic origin, which might be linked to the higher representation of GABAergic inhibition and projection in the rat IC.

The brainstem auditory nuclei, especially the dorsal and ventral nuclei of the lateral lemniscus as well as the superior paraolivary nucleus, have generally been considered to be a major source of inhibitory inputs to the neurons of the IC (ipsi- and contralaterally) (Zhang et al., 1998; Kulesza and Berrebi, 2000; Riquelme et al., 2001; Saldaña et al., 2009). However, the number of rat CIC GABAergic neurons, i.e., 30\% of 200,000-230,000, which are either local circuit neurons or projecting neurons sending local collaterals within the IC (Oliver et al., 1991; Malmierca et al., 1995b; Ito et al., 2009), is markedly higher than the number of GABAergic neurons in all the lower brainstem auditory nuclei in total. Therefore, the most important source of GABAergic terminals on the rat IC neurons might be the intrinsic GABAergic IC neurons themselves.

Recently, two types of GABAergic neurons were described in the IC of the rat with different synaptic organization and axonal projections: smaller GABAergic neurons, which are predominatly local circuit interneurons, and larger GABAergic neurons, 


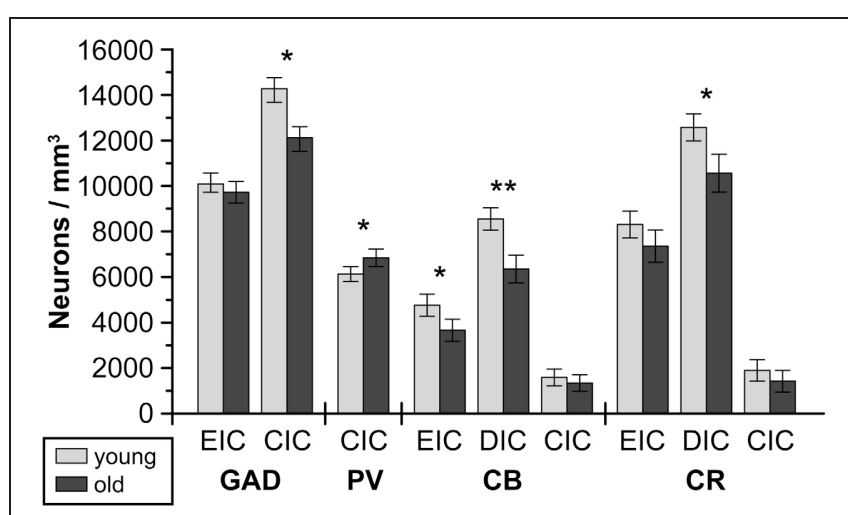

FIGURE 3 | The numerical density of GAD67-ir, PV-ir, CB-ir and CR-ir neurons in the external and dorsal cortices and in the central nucleus of the IC in young and old Long-Evans rats. $\mathrm{CIC}$, central nucleus of the inferior colliculus; DIC, dorsal cortex of the inferior colliculus; EIC, external cortex of the inferior colliculus; GAD67, glutamate decarboxylase, isoform 67; PV, parvalbumin; CB, calbindin; CR, calretinin. The displayed results represent a summary of graphs from Ouda et al. (2008); Burianova et al. (2009); Ouda et al. (2012b). The error bars represent S.E.M. $\left(* P<0.05,{ }^{* *} P<0.01\right)$.

predominantly projecting to the MGB (Ito et al., 2009). The projecting GABAergic neurons are more prevalent in the central nucleus of the IC and are densely covered perisomatically with glutamatergic synaptic contacts that could allow them to fire easily and rapidly. The exclusive presence of vesicular glutamate transporter 2 in presynaptic terminals suggests that the predominant sources of these synaptic connections are either collateral branches of IC glutamatergic neurons or fusiform cells in the dorsal cochlear nucleus. In addition, they possess very thick axons which may allow them to deliver inhibitory input to the MGB in advance of excitatory inputs from the glutamatergic IC neurons firing simultaneously (Ito et al., 2009).

In our previous study, we concluded that a minor neuronal population of about $10 \%$ of the neurons in all three major subdivisions of the IC of the rat expresses non-phosphorylated neurofilaments labeled by SMI-32 antibody (Ouda et al., 2012a). The SMI-32 antibody was shown to specifically label a subset of cortical and subcortical neurons in the mammalian brain, predominantly those with long and thick axonal projections (Sternberger and Sternberger, 1983; Kirkcaldie et al., 2002; Voelker et al., 2004; Molnár and Cheung, 2006). The non-phosporylated neurofilament content in neurons is thought to be associated with the large extent of axonal myelination and with large neuronal size (Campbell and Morrison, 1989; Tsang et al., 2000; Kirkcaldie et al., 2002). Since the GABAergic neurons in the rat IC are reported to be larger than non-GABAergic cells (Merchán et al., 2005), and simultaneously projection GABAergic neurons in the $\mathrm{CIC}$ and EIC, containing thick myelinated axons, are thought to be larger than non-projecting GABAergic neurons (Ito et al., 2009), we might speculate that the non-phosphorylated neurofilaments labeled by SMI-32 in the IC are preferentially expressed in a subset of the larger projecting GABA-ergic neuronal subpopulation. However, a double labeling study is necessary to confirm such a hypothesis.

\section{CALCIUM BINDING PROTEINS}

The calcium binding proteins (CBPs), CB, PV, and CR, represent major fast cytoplasmatic calcium buffers in the central nervous system and thus protect neurons from insults that induce an elevation of intracellular $\mathrm{Ca}^{2+}$ (Baimbridge et al., 1992; Elston and González-Albo, 2003). The disruption of neuronal calcium homeostasis and consequent molecular events affect neuronal viability and synaptic plasticity and may represent early steps in the development of neuronal degeneration (Foster, 2007). Changes in calcium homeostasis in the brain during aging or during different pathologies are thought to be tightly linked to a decline in neuronal performance (Khachaturian, 1989; Verkhratsky and Toescu, 1998; Toescu et al., 2004).

The distribution of calbindin-immunoreactive (CB-ir), calretinin immunoreactive (CR-ir) and parvalbumin-immunoreactive (PV-ir) neurons in the central nervous system of the rat was first described in summary by Celio (1990) and Résibois and Rogers (1992). Their distribution seems to be complementary to some extent with the major occurrence of $\mathrm{PV}$ in the primary (tonotopic) and $\mathrm{CB}$ and $\mathrm{CR}$ in the non-primary rat auditory regions (Lohmann and Friauf, 1996), as also described in mice (Cruikshank et al., 2001), chinchillas (Kelley et al., 1992), monkeys (Jones, 2003), and humans (Tardif et al., 2003; Sharma et al., 2009). Specifically in the IC, CB-ir, and CR-ir neurons are abundant in the dorsal and external cortices and relatively rare in the central nucleus of the IC, while PV-ir neurons are present in all three parts of the IC, with a predominant distribution in the CIC. The mutual colocalization of $\mathrm{CB}, \mathrm{PV}$, and $\mathrm{CR}$ in one neuron is known to be relatively rare, as they mainly represent three distinct neuronal populations; in the higher parts of the auditory pathway their expression is mostly found (in the case of PV almost exclusively) in GABAergic neurons (Demeulemeester et al., 1989; Kubota et al., 1994; Gonchar and Burkhalter, 1997; Jinno and Kosaka, 2002; Markram et al., 2004; Gonchar et al., 2007).

\section{PARVALBUMIN}

PV-ir neurons are present in all three subdivisions of the rat IC (Lohmann and Friauf, 1996; Ouda et al., 2008). In the CIC, neurons with a large variation in the size of their neuronal somas are rather uniformly distributed (Figure 2B). In our PVir staining, the intensity of their immunoreactivity varied from low to high and their morphology resembles the less-flat cells, similarly as in GAD immunostaining. In the EIC, the majority of PV-ir neurons belonged to the large spindle-like multipolar cells and smaller oval neurons (Ouda et al., 2008). The clusters of PV-immunoreactive somas and neuropil in the second layer of the EIC are very similar to the clusters in GAD immunostaining and visible in practically all examined rats, as in GAD immunostaining (Chernock et al., 2004; Ouda et al., 2008). The DIC contains a relatively low number of mostly oval, small-sized PV-immunoreactive neurons (Lohmann and Friauf, 1996; Ouda et al., 2008).

In the neocortex, the PV-expressing neurons mostly form a well-defined population of fast-spiking GABA-ergic basket cells that are essential for the generation of gamma oscillations, which are thought to provide a temporal framework for information processing in the brain (Kawaguchi and Kubota, 1998; Bartos 
et al., 2007). These neurons comprise roughly $40-50 \%$ of all cortical GABAergic neurons; practically all PV-ir cortical cells are also GABAergic cells (Gonchar and Burkhalter, 1997; Gonchar et al., 2007). The co-expression of GAD and the functional importance of the PV-ir neuronal population in the IC are known to a lesser extent. From our experiments (Ouda et al., 2008), we can estimate that the number of GAD-ir neurons in the rat IC is roughly two times higher in the central nucleus and external cortex of the IC than the number of PV-ir neurons (Figure 3). On the other hand, Fredrich et al. (2009) identified almost all GAD-ir neurons in the central nucleus of the rat IC as co-expressing PV. The reason for this discrepancy is not clear; however, the different antibodies used and variations in the immunoreactivity of PV-ir somas pivotal for classifying a cell as PV-positive might be responsible to some degree for this difference. The potential preference for PV expression in some GABAergic subpopulations, especially larger GABAergic neurons projecting to the MGB vs. smaller local circuit interneurons (Ito et al., 2009), is open to further investigation. However, the PV-ir neurons in the CIC varied in size from small to large-sized in our staining, similarly as for GAD immunostaining (Ouda et al., 2008; Burianova et al., 2009), which may suggest the presence of PV in both of the above-mentioned GABAergic subpopulations.

In any case, the distribution of PV-ir neurons in the whole IC reflects relatively well the distribution of GABAergic (GAD-ir) neurons (compare Figures $\mathbf{2 A}$ and $\mathbf{2 B}$ ). Furthermore, the morphological types, at least of the neuronal somas, present in our immunostainings correspond relatively well to the same classification of GAD-ir neurons discussed in the previous section on GAD. In addition, the similar appearance of clusters in the EIC in both GAD and PV immunostaining (Chernock et al., 2004) supports the idea of a strong overlap of GAD and PV immunoreactivity in the IC. In addition, only one group of cellular clusters in the second layer of the EIC was evaluated by Malmierca et al. (2011) with Rio-Hortega Golgi staining. However, the precise extent of these overlaps, even in the discussed clusters in the second layer of the EIC, requires a double labeling study to determine, which has not yet been performed in the EIC.

\section{CALBINDIN}

CB-ir neurons are present in all three subdivisions of the rat IC; however, the majority of CB-ir cells are found in the dorsal and external cortices, while only a few weakly stained neurons are scattered throughout the central nucleus of the IC (Förster and Illing, 2000; Ouda et al., 2012b) (Figure 2C).

A relatively homogenous neuropil and a high numerical density of CB-ir neurons are typical for the rat DIC, with a gradual decrease from the cortical surface toward the borders with the central nucleus. The neuronal somata are mainly oval or polygonal with loosely stained dendrites (Ouda et al., 2012b). In the rat EIC, the numerical density of immunoreactive cells is lower (Figure 3) and decreases toward the CIC and toward the basal part of the IC. The cellular morphology in the EIC is more heterogenous with oval, elongated or triangular somas. No signs of cluster-like immunoreactivity are present in the EIC (Chernock et al., 2004; Ouda et al., 2012b). In both the DIC and CIC, the highest numerical density of CB-ir neurons can be found adjacent to the surface of the IC and decreases toward the central nucleus. The CIC is demarcated as an area with low CB neuropil staining and weakly stained sparse CB-ir neurons (Förster and Illing, 2000; Ouda et al., 2012b).

As mentioned previously, CBPs were reported to be expressed mostly by GABAergic neurons (Freund and Buzsáki, 1996; Gonchar and Burkhalter, 1997; Gonchar et al., 2007); however, calbindin most likely does not follow this rule. For example, some weakly stained CB-ir cells in the superficial cortical layers of the neocortex are known to be pyramidal neurons (Kubota et al., 1994; De Felipe, 1997). In the IC, the notable prevalence of calbindin (and also calretinin) in the dorsal and external cortices and its low occurrence in the CIC suggest that at least some of these neurons are not GABAergic. This suggestion is further supported by the fact that in our quantitative estimates, we found that the numerical density of calbindin- and calretinin-immunoreactive neurons in the DIC is even higher than the number of all GAD-ir neurons in the DIC (unpublished data). In addition, clusters of smaller oval neurons that are GAD-ir and PV-ir in the EIC are not visible in calbindin immunostaining (Ouda et al., 2012b). No double labeling study in the DIC or EIC has been undertaken so far, while in the CIC, Fredrich et al. (2009) did not report the colocalization of GABA and $\mathrm{CB} / \mathrm{CR}$ using double staining.

\section{CALRETININ}

CR-ir neurons are found in all three subdivisions of the rat IC with a significant presence in the dorsal and external cortices (Lohmann and Friauf, 1996; Ouda et al., 2012b) (Figure 2D). In the CIC, a weaker positivity of the neuropil and a lower numerical density of CR-ir neurons are distinctive features, while in the DIC, a relatively homogenous neuropil and a very high numerical density of CR-ir neurons are dominant features (Ouda et al., 2012b).

In the rat EIC, an interesting feature of $\mathrm{CR}$ immunostaining that we could often find in our sections stained for calretinin is a strip-like distribution of CR-ir neurons and neuropil positivity throughout all three cortical layers, with patches with a higher concentration of immunoreactive neuropil and neurons that are surrounded by less stained neuropil. One might speculate about a link to the clusters evaluated by Chernock et al. (2004) that display GAD, parvalbumin and NADPH-diaphorase immunoreactivity. However, these pro tempore called strips or patches are not delineated as clearly and consistently or with such contrast as the clusters in GAD or PV immunostaining; furthermore, they are larger and situated deeper from the IC surface across the EIC (Figure 2D). Dual labeling will be necessary to determine any such potential relationship. The form of the CR-ir neuronal somas in the EIC ranges from small-sized to large neurons and oval or polygonal in shape, while a few cells with spindle-like morphology are present (Ouda et al., 2012b).

The correspondence of calretinin-expressing neurons with particular morphological types and specifically with the GABAmediated system in the IC is more ambiguous than in the case of parvalbumin. As stated above, the numerical density of calbindinand calretinin-immunoreactive neurons in the DIC is even higher than the number of all GAD-ir neurons in the DIC. However, in contrast to calbindin, the presence of a few large spindle-like 
neurons and potential cluster-like immunoreactivity suggests a more pronounced overlap with the population of GAD-ir neurons, at least in the external cortex of the IC.

Interestingly, the distribution and numerical density of CR-ir neurons throughout the IC are similar to the distribution and numerical density of neurons positive for NADPHdiaphorase $(-\mathrm{d})$, which identifies neurons capable of producing nitric oxide (Dawson et al., 1991; Hope et al., 1991; Druga and Syka, 1993; Loftus et al., 2008; Wu et al., 2008). In our estimation, the numerical density of NADPH-d-positive neurons in all three major divisions of the IC is close to the numerical density of CRir neurons (unpublished data). In the IC, the NADPH-d-positive neuronal subpopulation is known to be predominantly glutamatergic, while only a minority of NAPDH-diaphorase-positive cells in the IC is GABAergic neurons (Wu et al., 2008). No double labeling study of CR and NADPH-d was reported in the IC; however, a substantial colocalization of CR and NADPH-d expression in neurons was observed in the hippocampus and periaqueductal gray (Czéh et al., 2005; Barbaresi et al., 2012). On the other hand, the pattern of clusters in the second layer of the EIC labeled by NADPH-d staining apparently corresponds to the pattern of the clusters present in GAD and PV immunostaining (Chernock et al., 2004).

\section{INFLUENCE OF AGING ON THE EXPRESSION OF IMMUNOCYTOCHEMICAL MARKERS}

The inferior colliculus, similarly as other structures of the auditory pathway in the rat, undergoes essential changes with aging. To demonstrate these changes clearly, we decided to use for aging studies two rat strains (the inbred Fischer 344 strain and the outbred Long-Evans strain) with a wide variety of morphological, physiological and behavioral differences, including differently preserved hearing function with age (for review see Syka, 2010). For example, similarly as with other inbred strains, Fischer 344 rats display large cognitive deficits in different tests of spatial memory in the Morris water maze in contrast to wild rats and Long-Evans rats (Harker and Whishaw, 2002). While Long-Evans rats represent a strain with relatively well preserved peripheral hearing function up to late senescence, a rapid and pronounced deterioration of hearing function with aging is found in Fischer 344 rats, resulting in larger hearing threshold shifts, a decrease in the amplitude of click-evoked auditory brainstem responses, a diminution of distortion product otoacoustic emissions and a decrease in middle-ear compliance (Popelar et al., 2003, 2006). Age-related sensory deficits in F344 rats also include visual function, which is damaged due to retinal degeneration (Di Loreto et al., 1994). In spite of the differences between strains, we found that age-related changes in the immunocytochemical markers in the IC were almost identical in both strains.

\section{GLUTAMATE DECARBOXYLASE}

In GAD-65 and 67 immunoreactivity (Burianova et al., 2009), significant declines with aging were observed in the CIC and EIC comprising a decrease in the optical density of GAD-ir neuronal somas and a decrease in the number of GAD-ir cells (CIC only, Figure 3). These findings were supported by the results of western blot analysis that demonstrated a significant age-related decline of about 50\% in the levels of GAD65 and GAD67 proteins in the IC of old rats in comparison with young animals (Figure 4). The analyzed samples for western blotting included the whole IC (i.e., all three subdivisions of the IC at once). The decline in GAD immunoreactivity was also similar in the auditory cortex, and the pattern of changes was very similar in both Long-Evans and Fischer 344 animals. Interestingly, the protein levels of both isoforms of glutamate decarboxylase (GAD65 and 67) were found to be approximately threefold higher (per unit of tissue weight) in the rat IC in comparison with the neocortical areas in both young and old animals (Sheikh et al., 1999; Burianova et al., 2009), which might further support a prominent role for inhibition in the rat IC.

An age-related decrease in the number of GABAimmunoreactive cells associated with a decrease in enzymatic activity, the levels of GABA and the release of GABA in the rat CIC was also reported by other authors (Caspary et al., 1990, 1995; Gutiérrez et al., 1994; Raza et al., 1994). Simultaneously, GABA-A and GABA-B receptor binding intensity was reported to decline, and the protein levels of the receptor subunits were found to be altered during aging in the IC of Sprague-Dawley and Fischer 344 rats (Gutiérrez et al., 1994; Milbrandt et al., 1994; Caspary et al., 1999; Schmidt et al., 2010). The compromised GABA-mediated inhibition in the IC could consequently result in a broadening of the excitatory areas and thus in the poorer tuning of the neuronal receptive fields. In turn, the reduction of fine-tuned receptive fields resulted in a poorer discrimination of the temporal parameters of sounds, as also demonstrated by

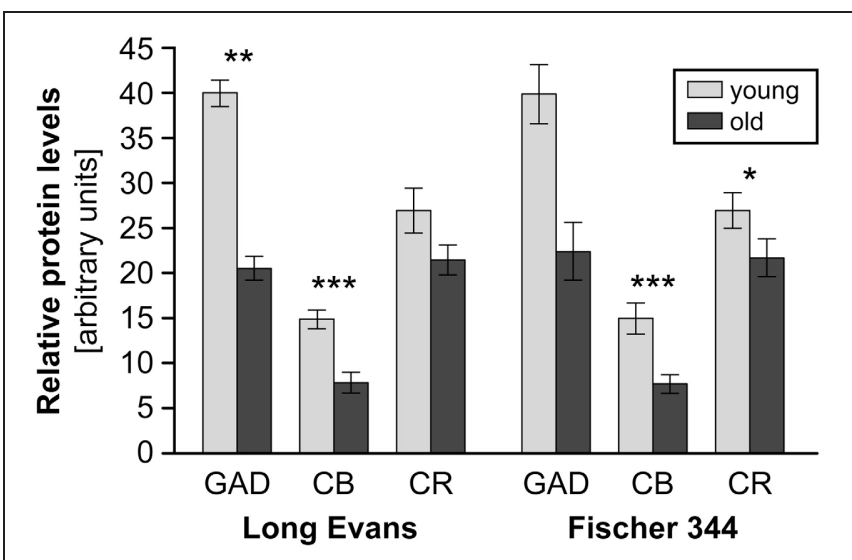

FIGURE 4 | The results of western blot protein analysis of GAD67, calbindin (CB) and calretinin (CR) in the IC of young and old

Long-Evans and Fischer $\mathbf{3 4 4}$ rats. Arbitrary units were calculated as the ratio between the optical density of the examined protein and the optical density of actin (in scanned films analysed using ImageQuant software). The heights of the columns for GAD67, CB, and CR cannot be mutually compared; they are dependent on the ratio of protein levels between the IC and the cortical areas for each examined protein. The tall column for GAD67 (in arbitrary units) indicates a larger amount of GAD67 per unit tissue weight in the IC when compared to the cortex (and conversely for $\mathrm{CB}$ ). Due to the limited number of old Fischer 344 rats available for GAD67 protein analysis, the data did not demonstrate statistically significant differences in this case. The graph is constructed from data presented in Burianova et al. (2009); Ouda et al. (2012b). The error bars represent S.E.M. ${ }^{*} P<0.05$, ** $\left.P<0.01,{ }^{* * *} P<0.001\right)$. 
electrophysiological data in the IC (Palombi and Caspary, 1996; Walton et al., 1998, 2002; Simon et al., 2004).

\section{CALCIUM BINDING PROTEINS}

Despite the almost exclusive colocalization of GABA-ir and PVir in neurons in the IC and neocortex (Gonchar and Burkhalter, 1997; Gonchar et al., 2007; Fredrich et al., 2009), the age-related changes in parvalbumin immunoreactivity were different when compared with changes in GAD 65 and 67 (Ouda et al., 2008). In old Long Evans rats, the observed changes were rather mild: the number of PV-ir neurons in the CIC was slightly increased, associated with an increase in the optical density of PV-ir somas and a slight decrease in the mean neuronal volumes. In contrast, in old Fischer 344 rats a non-significant tendency toward a decrease in the number of PV-ir neurons in the IC and significantly smaller mean neuronal volumes were present. The observed changes could not be attributed to any specific type of neuron. In contrast to these findings, a significant reduction in the occurrence of PV-ir neurons was found in the auditory cortex of Fischer 344 animals with aging, whereas in Long Evans rats such a reduction was not observed.

The age-related changes in calbindin and calretinin immunoreactivity had a rather similar pattern and were relatively uniform, regardless of the examined rat strain or structure (IC and auditory cortex). We found similar significant age-related changes in $\mathrm{CB}$ immunoreactivity in the dorsal and external cortices of both Long Evans and Fischer 344 rats. The changes included a decrease in the number of $\mathrm{CB}$-ir neurons and a significant decline in the average volumes of $\mathrm{CB}$-ir neuronal somas (DIC only). In western blotting, the age-related changes were even more pronounced and resulted in a significant decline in the levels of calbindin in the whole IC of old rats of both species of almost 50\%. In calretinin immunoreactivity, a tendency toward an age-related decline in the number of CR-ir neurons as well as a significant decrease in the mean volumes of the remaining CR-ir neuronal somas were found in the dorsal and external cortices of the IC. Western blot analysis demonstrated a significant decline, however, less pronounced when compared to calbindin and GAD, in calretinin protein levels of $22 \%$ in both rat strains (Ouda et al., 2012b). Summaries of the immunohistochemical age-related findings and western blot results are presented in Figures 3, 4.

In an inter-species comparison, strain-dependent differences were found in the inferior colliculus of the $\mathrm{CBA} / \mathrm{CaJ}$ and C57/BL/6J mouse strains: with aging, both strains showed a decline in the number of calbindin-ir neurons in the IC, similarly as in our study. However, the number of CR-ir neurons did not change with age in C57 mice and even significantly increased in the IC of CBA mice (a mouse strain with preserved hearing function up to an advanced age) (Zettel et al., 1997). In the case of calretinin, the changes were found to be activity-dependent, since early bilateral deafening prevented calretinin up-regulation in the DIC of aged CBA animals (Zettel et al., 2001). This difference from the findings in Long-Evans rats might reflect inter-species differences to some degree. A decline in the number of calcium binding protein $(\mathrm{CBP})$-ir neurons were observed in different brain neocortical areas in humans, including the auditory cortex, without any previous signs of psychiatric or neurological diseases (Bu et al., 2003). Increasing evidence has also accumulated about the mutual links among intracellular calcium regulation, alterations in intracellular CBP levels and neurodegenerative and neuropsychiatric disorders (for review see Woo and Lu, 2006; Mattson, 2007). The disruption of calcium homeostasis in neurons may consequently be involved in both the impairments that accompany normal aging and also in the different pathologies associated with age-related disorders (Khachaturian, 1989; Foster, 2007; Mattson, 2007; Riascos et al., 2011). In this context, it may be surprising that in mutant mice (CB-/-, CR-/- or PV-/-), the deleted individual CBP is not compensated for by the upregulated expression of any other CBP (Schwaller et al., 2002). Nevertheless, the mice (of all three types) are not only able to survive, but actually display no significant changes in phenotype, either in the general morphology of the nervous system or their behavior under normal housing conditions. The morphological and functional changes are rather subtle and manifest during specific behavioral experiments, which may suggest a more complicated function for CBPs in neurons, not only as simple calcium buffers and thus as neuroprotective molecules, but also as complex components in intracellular calcium homeostasis involved in the subtle regulation and timing of calcium signals pre- or postsynaptically (Schwaller et al., 2002; Schwaller, 2010).

\section{CHANGES IN THE TOTAL NUMBER OF NEURONS}

The decreased number of immunoreactive neurons (GAD-, CB-, CR-ir, etc.,) in the IC observed in aging studies cannot be easily attributable to a general neuronal loss, because in our previous experiments we found that the reduction in the total number of neurons in the IC of old Long-Evans and Fischer 344 rats in Nissl-stained sections does not exceed 10\% (unpublished data). This finding is in agreement with the data of other authors, who reported no significant changes accompanying aging in the total number of neurons in the rat inferior colliculus (Helfert et al., 1999) or other rat brain regions, including the hippocampus and cortical areas (Merrill et al., 2001; Poe et al., 2001; Stanley and Shetty, 2004). Specifically, in the IC of old Fischer 344 rats, the number of both inhibitory and excitatory synaptic terminals decreased while no age-related reduction in the total number of neurons was found (Helfert et al., 1999). For comparison, a stereological study demonstrated an age-related decrease in the total number of neurons in the human neocortex of fewer than $10 \%$ (Pakkenberg and Gundersen, 1997).

Therefore, the diminished expression of proteins in originally immunoreactive neurons may be the reason for the age-related reduction in the detectable numbers of immunoreactive neurons. Similarly, up-regulated or de novo expression in previously nonexpressing neurons may be the reason for the increase in the number of immunoreactive neurons in situations such as the reported increase of CR-ir neurons in the IC of old CBA mice (Zettel et al., 1997).

\section{THE LINK TO ELECTROPHYSIOLOGICAL AND BEHAVIORAL DATA}

So far, it has not been known whether the age-related changes in the IC (and/or auditory cortex) are mainly the consequence of decreased ascending inputs from the deteriorated periphery or 
rather part of the changes in the aging brain itself. Most immunohistochemical experiments concerning age-related changes in the GABA-mediated inhibition of central auditory system were undertaken in animal strains with a pronounced hearing loss and deterioration of the peripheral sensory organ with aging, which represented a complication for determining the cause of the observed changes (for review see Frisina, 2001, 2009, 2010; Syka, 2002; Caspary et al., 2008). In our experiments, the age-related decline in the number of GAD-ir, CB-ir, and CR-ir neurons as well as the decline in $\mathrm{GAD}, \mathrm{CB}$, and $\mathrm{CR}$ protein levels in the inferior colliculus (and auditory cortex) were found to be largely independent of the peripheral deterioration, including the levels of the hearing threshold shifts (Burianova et al., 2009; Ouda et al., 2012b).

Hearing function was shown to be altered in the absence of any significant damage to the peripheral sensory organ, since the age-related worsening of gap detection thresholds, the gap duration difference limen and the disappearing middle latency response to an increasing stimulus repetition rate are not correlated with hearing threshold shifts in Long-Evans rats (Suta et al., 2011). Specifically, the gap detection thresholds were shown to be based predominantly on subcortical structures, since the induced temporary inactivation of the left auditory cortex in the rat by the administration of muscimol resulted in a significant worsening of the gap duration difference limen, while gap detection thresholds were not significantly changed (Rybalko et al., 2010). Furthermore, the neural code necessary for behavioral gap detection is present in the temporal discharge patterns of the majority of IC neurons (Walton et al., 1997).

Similarly, in electrophysiological studies on aging Fischer 344 rats, the reduction in the maximum discharge rate or the increased number of units responding poorly to an auditory stimulus in the IC was not correlated with the observed hearing threshold shift. In addition, for spontaneous activity, first spike latency or dynamic range, no significant declines were observed with aging (Palombi and Caspary, 1996). Also in mice, spontaneous rates and the distribution of temporal discharge patterns did not differ significantly between young and old CBA/CaJ mice, and the age-related decline in the processing of temporal sound features or the coding of envelope periodicities was suggested to be likely related to a dysbalance between inhibitory and excitatory neuronal mechanisms (Walton et al., 1998, 2002). Significant central functional age-related hearing alterations in the IC were found in both the CBA/CaJ mouse strain, with relatively preserved peripheral hearing up to late senescence, and the C57/BL/6J mouse strain, which serve as a model of rapid and severe sensorineural presbycusis, though the particular character of the changes was different (Walton et al., 1998, 2002; Felix and Portfors, 2007).

In a recent age-related study, (Rybalko et al., in press) performed in our laboratory, the acoustic startle reflex (ASR) (a transient motor response to an intense unexpected stimulus) and the prepulse inhibition (PPI) were used as an indicator of the behavioral responsiveness to sound stimuli. While the ASR is an unconditioned reflex reaction, in the PPI procedure, the startle reaction is inhibited by a low-level sound that shortly precedes the intense startle stimulus (Davis et al., 1982; Koch, 1999). Animal studies have shown that in the auditory system, PPI is involved in the cochlear nucleus, the inferior and superior colliculi and the pedunculopontine tegmental nucleus (Nodal and López, 2003), with the cortex and hippocampus exhibiting a modulatory effect on the PPI (Koch, 1999). The PPI of ASR, which represents a basic inhibitory process regulating sensory inputs, can be used for estimating age-related changes in inhibitory function (Geyer and Braff, 1987; Swerdlow et al., 2001). In our experiments, both Long-Evans and Fischer 344 rats exhibited a similar age-related progression of PPI deterioration, with a significantly decreased inhibitory efficacy in aged rats. This decrease was not correlated with the observed hearing threshold shifts.

Therefore, we may suggest that the age-related decline in GAD expression in the rat IC and AC, as demonstrated in our experiments, does not depend exclusively on peripheral deafferentation but is, at least partially, of central origin. The age-related alterations in the IC involving the GABA-mediated inhibitory system and the decline in the number of neurons expressing glutamate decarboxylase and CBPs may significantly contribute to the observed behavioral impairment.

\section{THE REVERSIBILITY OF CHANGES AND FUNCTIONAL IMPLICATIONS}

The potential long-term reversibility or compensation of the agerelated changes in the expression of glutamate decarboxylase or CBPs is open to further investigation. However, it is known that changes in the expression of selected neuronal markers in the IC neurons, including CBPs that are induced by experimental manipulations may be reversible to some extent.

For example, following monoaural cochlear ablation in the ferret, the CR-ir plexus in the contralateral CIC increased its optical density and the area of immunostaining (Fuentes-Santamaria et al., 2003). The increase in CR immunostaining was interpreted as an up-regulation of CR expression in a subset of IC afferents. In rats, a similar increase in the levels of CR was found after unilateral enucleation in the contralateral superior colliculus (Arai et al., 1993). Furthermore, the induced changes were found to be reversible to some degree after a longer time period. A unilateral ablation of the auditory cortex in rats resulted in a progressive increase in the number and optical density of CR-ir neurons in the dorsal and external cortices, i.e., the subdivisions of the IC more inervated by the cortico-collicular projection, which returned to control values during the long-term survival of the animals (Clarkson et al., 2010). Similarly, the number of NADPH-d-positive neurons in the inferior colliculus declined significantly after a lesion of the auditory cortex at short survival intervals in rats; however, this reduction diminished after longer survival intervals (Druga and Syka, 2001). The reversible character of the changes in protein expression supports the idea of the preservation of the affected neurons.

With respect to studies on aging, similar data are very limited. At the cortical level, a partial recovery of age-related deterioration was shown by De Villers-Sidani et al. (2010). The age-related hearing deficits and the decline in the number of PV-ir neurons in the auditory cortex of old rats were partially reversed after intensive auditory behavioral training. Similarly, in the visual cortex of old monkeys, deteriorated GABA-mediated function was observed with aging, while the local administration of GABA 
temporarily improved the visual function of the neurons (Leventhal et al., 2003). Nevertheless, despite peripheral deterioration that leads to reduced input thoughout the auditory pathway to the IC and central neurochemical changes affecting the levels of neurotransmitters or CBPs, the compensatory mechanisms are probably highly active in sensory systems in aged animals and humans, as also emphasized by other authors (Palombi and Caspary, 1996; Syka, 2002; Caspary et al., 2008; Frisina, 2010).

\section{CONCLUSIONS}

The inferior colliculus may play an even more prominent role in the central auditory system of rats than usually thought, since the rat IC contains more neurons in total than all other subcortical auditory structures combined (Kulesza et al., 2002; Ouda et al., 2012a). In addition, inhibitory neurons in the rat IC, including GABAergic projections from the IC to the MGB, are present in abundant numbers when compared to the cat or bat, whereas intrinsic GABAergic neurons are practically absent in the MGB of rats and other rodents in contrast to other mammalian orders (Winer and Larue, 1996; Merchán et al., 2005; Ito et al., 2009).

Along with the auditory cortex, the IC plays a key role in the processing of the temporal parameters of sounds, which is strongly dependent on the function of the inhibitory systems. Both temporal parameter processing and GABA-mediated inhibition are known to be altered in aged rats (Syka, 2002; Caspary et al., 2008; Frisina, 2010). The decline in the number of neurons expressing glutamate decarboxylase and CBPs as well as the decline in the levels of these proteins occuring in the IC with

\section{REFERENCES}

Aitkin, L. M., Dickhaus, H., Schult, W., and Zimmermann, M. (1978). External nucleus of inferior colliculus: auditory and spinal somatosensory afferents and their interactions. J. Neurophysiol. 41, 837-847.

Arai, M., Arai, R., Sasamoto, K., Kani, K., Maeda, T., Deura, S., and Jacobowitz, D. M. (1993). Appearance of calretininimmunoreactive neurons in the upper layers of the rat superior colliculus after eye enucleation. Brain Res. 613, 341-346.

Baimbridge, K. G., Celio, M. R., and Rogers, J. H. (1992). Calciumbinding proteins in the nervous system. Trends Neurosci. 15, 303-308.

Barbaresi, P., Quaranta, A., Amoroso, S., Mensà, E., and Fabri, M. (2012). Immunocytochemical localization of calretinin-containing neurons in the rat periaqueductal gray and colocalization with enzymes producing nitric oxide: a double, double-labeling study. Synapse 66, 291-307.

Bartos, M., Vida, I., and Jonas, P. (2007). Synaptic mechanisms of synchronized gamma oscillations in inhibitory interneuron networks. Nat. Rev. Neurosci. 8, 45-56.

Batra, R., and Fitzpatrick, D. C. (2002). Monaural and binaural processing in the ventral nucleus of the lateral lemniscus: a major source of inhibition to the inferior colliculus. Hear. Res. 168, 90-97.

Beyerl, B. D. (1978). Afferent projections to the central nucleus of the inferior colliculus in the rat. Brain Res. 145, 209-223.

$\mathrm{Bu}$, J., Sathyendra, V., Nagykery, N., and Geula, C. (2003). Agerelated changes in calbindin-D28k, calretinin, and parvalbuminimmunoreactive neurons in the human cerebral cortex. Exp. Neurol. $182,220-231$.

Burianova, J., Ouda, L., Profant, O., and Syka, J. (2009). Age-related changes in GAD levels in the central auditory system of the rat. Exp. Gerontol. 44, 161-169.

Campbell, M. J., and Morrison, J. H. (1989). Monoclonal antibody to neurofilament protein (SMI-32) labels a subpopulation of pyramidal neurons in the human and monkey neocortex. J. Comp. Neurol. 282, 191-205.

aging, as observed in our experiments, could represent a basis for central functional deterioration (Ouda et al., 2008, 2012b; Burianova et al., 2009). Since the total number of neurons in the IC likely does not decline significantly with aging (Helfert et al., 1999), the diminished expression of proteins in originally immunoreactive neurons may be the reason for the age-related reduction in the detectable numbers of immunoreactive neurons. Furthemore, the age-related decline in the number of immunoreactive neurons and the levels of the proteins occurring in the central auditory system is not exclusively dependent on the loss of peripheral inputs, but may represent, at least partially, a feature of the aging brain and significantly contribute to the deterioration of hearing function known as central presbycusis.

Central presbycusis represents a complex process that includes alterations present in the subcortical auditory nuclei, the auditory cortex and other non-auditory regions, as well as the development of partial compensatory mechanisms. The potential reversibility or compensation of these age-related changes is open to further investigation. A better understanding of the mechanisms underlying impaired neuronal processing in the central auditory system with aging, resulting in the poor recognition of complex environmental sounds, species-specific vocalizations in animals and speech in man, may have important implications for the treatment or amelioration of the negative aspects of presbycusis in the future.

\section{ACKNOWLEDGMENTS}

This study was supported by the Grant Agency of the Czech Republic P304/12/1342 and P304/12/G069.

Caspary, D. M., Raza, A., Lawhorn Armour, B. A., Pippin, J., and Arneric, S. P. (1990). Immunocytochemical and neurochemical evidence for age-related loss of GABA in the inferior colliculus: implications for neural presbycusis. J. Neurosci. 10, 2363-2372.

Caspary, D. M., Holder, T. M., Hughes, L. F., Milbrandt, J. C., McKernan, R. M., and Naritoku, D. K. (1999). Age-related changes in GABAA receptor subunit composition and function in rat auditory system. Neuroscience 93, 307-312.

Caspary, D. M., Ling, L., Turner, J. G., and Hughes, L. F. (2008). Inhibitory neurotransmission, plasticity and aging in the mammalian central auditory system. J. Exp. Biol. 211, 1781-1791.

Caspary, D. M., Milbrandt, J. C., and Helfert, R. H. (1995). Central auditory aging: GABA changes in the inferior colliculus. Exp. Gerontol. 30, 349-360.

Casseday, J. H., Ehrlich, D., and Covey, E. (2000). Neural measurement of sound duration: control by excitatory-inhibitory interactions in the inferior colliculus. J. Neurophysiol. 84 , 1475-1487.

Casseday, J. H., Fremouw, T., and Covey, E. (2002). "The inferior colliculus: a hub for the central auditory system," in Integrative Functions in the Mammalian Auditory Pathway, Vol. 15, eds D. Oertel, A. N. Popper, and R. R. Fay (New York, NY: Springer-Verlag), 238-318.

Celio, M. R. (1990). Calbindin D-28k and parvalbumin in the rat nervous system. Neuroscience 35, 375-475.

Chernock, M. L., Larue, D. T., and Winer, J. A. (2004). A periodic network of neurochemical modules in the inferior colliculus. Hear. Res. 188, 12-20.

Clarkson, C., Juíz, J. M., and Merchán, M. A. (2010). Long-term regulation in calretinin staining in the rat inferior colliculus after unilateral auditory cortical ablation. J. Comp. Neurol. 518, 4261-4276.

Cruikshank, S. J., Killackey, H. P., and Metherate, R. (2001). Parvalbumin and calbindin are differentially distributed within primary and secondary subregions of the mouse auditory forebrain. Neuroscience $105,553-569$. 
Czéh, B., Hajnal, A., and Seress, L. (2005). NADPH-diaphorase positive neurons of the rat hippocampal formation: regional distribution, total number and colocalization with calcium binding proteins. Prague Med. Rep. 106, 261-274.

Davis, K. A. (2002). Evidence of a functionally segregated pathway from dorsal cochlear nucleus to inferior colliculus. J. Neurophysiol. 87, 1824-1835.

Davis, M., Gendelman, D., Tischler, M., and Gendelman, P. (1982). A primary acoustic startle circuit: lesion and stimulation studies. J. Neurosci. 6, 791-805.

Dawson, T. M., Bredt, D. S., Fotuhi, M., Hwang, P. M., and Snyder, S. H. (1991). Nitric oxide synthase and neuronal NADPH diaphorase are identical in brain and peripheral tissues. Proc. Natl. Acad. Sci. U.S.A. 88, 7797-7801.

De Felipe, J. (1997). Types of neurons, synaptic connections and chemical characteristics of cells immunoreactive for calbindin-D28K, parvalbumin and calretinin in the neocortex. J. Chem. Neuroanat. 14, 1-19.

De Villers-Sidani, E., Alzghoul, L., Zhou, X., Simpson, K. L., Lin, R. C., and Merzenich, M. M. (2010). Recovery of functional and structural age-related changes in the rat primary auditory cortex with operant training. Proc. Natl. Acad. Sci. U.S.A. 107, 13900-13905.

Demeulemeester, H., Vandesande, F., Orban, G. A., Heizmann, C. W., and Pochet, R. (1989). Calbindin D-28K and parvalbumin immunoreactivity is confined to two separate neuronal subpopulations in the cat visual cortex, whereas partial coexistence is shown in the dorsal lateral geniculate nucleus. Neurosci. Lett. 99, 6-11.

Diamond, J. T., Jones, E. G., and Powel, T. P. S. (1969). The projection of the auditory cortex upon the diencephalon and brainstem of the cat. Brain Res. 15, 305-340.

Di Loreto, D. Jr., Cox, C., Grover, D. A., Lazar, E., del Cerro, C., and del Cerro, M. (1994). The influences of age, retinal topography, and gender on retinal degeneration in the Fischer 344 rat. Brain Res. 647, 181-191.

Dorph-Petersen, K. A., Caric, D., Saghafi, R., Zhang, W., Sampson, A. R., and Lewis, D. A. (2009). Volume and neuron number of the lateral geniculate nucleus in schizophrenia and mood disorders. Acta Neuropathol. 117, 369-384.

Druga, R., and Syka, J. (1984a). Ascending and descending projections to the inferior colliculus in the rat. Physiol. Bohemosl. $33,31-42$.

Druga, R., and Syka, J. (1984b). Neocortical projections to the inferior colliculus in the rat. Physiol. Bohemosl. 33, 251-253.

Druga, R., and Syka, J. (1984c). Projections from auditory structures to the superior colliculus in the rat. Neurosci. Lett. 45, 247-252.

Druga, R., and Syka, J. (1993). NADPH-diaphorase activity in the central auditory structures of the rat. Neuroreport 4, 999-1002.

Druga, R., and Syka, J. (2001). Effect of auditory cortex lesions on NADPHdiaphorase staining in the inferior colliculus of rat. Neuroreport 12, 1555-1559.

Druga, R., Syka, J., and Rajkowska, G. (1997). Projections of auditory cortex onto the inferior colliculus in the rat. Physiol. Res. 46, 215-222.

Elston, G. N., and González-Albo, M. C. (2003). Parvalbumin-, calbindin-, and calretinin-immunoreactive neurons in the prefrontal cortex of the owl monkey (Aotus trivirgatus): a standardized quantitative comparison with sensory and motor areas. Brain Behav. Evol. 62, 19-30.

Erlander, M. G., Tillakaratne, N. J. K., Feldblum, S., Patel, N., and Tobin, A. J. (1991). Two genes encode distinct glutamate decarboxylase. Neuron 7, 91-100.

Erlander, M. G., and Tobin, A. J. (1991). The structural and functional heterogeneity of glutamic acid decarboxylase: a review. Neurochem. Res. 16, 215-226.

Esclapez, M., Tillakaratne, N. J., Kaufman, D. L., Tobin, A. J., and Houser, C. R. (1994). Comparative localization of two forms of glutamic acid decarboxylase and their mRNAs in rat brain supports the concept of functional differences between the forms. J. Neurosci. 14, 1834-1855.

Faye-Lund, H., and Osen, K. K. (1985). Anatomy of the inferior colliculus in rat. Anat. Embryol. 171, 1-20.

Feldblum, S., Erlander, M. G., and Tobin, A. J. (1993). Different distributions of GAD65 and GAD67 mRNAs suggest that the two glutamate decarboxylases play distinctive functional roles. J. Neurosci. Res. 34 689-706.

Felix, R. A. 2nd, and Portfors, C. V. (2007). Excitatory, inhibitory and facilitatory frequency response areas in the inferior colliculus of hearing impaired mice. Hear. Res. 228, 212-229.

Foster, T. C. (2007). Calcium homeostasis and modulation of synaptic plasticity in the aged brain. Aging Cell 6, 319-325.

Förster, C. R., and Illing, R. B. (2000). Plasticity of the auditory brainstem: cochleotomy-induced changes of calbindin-D28k expression in the rat. J. Comp. Neurol. 416, 173-187.

Fredrich, M., Reisch, A., and Illing, R. B. (2009). Neuronal subtype identity in the rat auditory brainstem as defined by molecular profile and axonal projection. Exp. Brain Res. 195, 241-260.

Freund, T. F., and Buzsáki, G. (1996). Interneurons of the hippocampus. Hippocampus 6, 347-470.

Frisina, D. R., and Frisina, R. D. (1997) Speech recognition in noise and presbycusis: relations to possible neural mechanisms. Hear. Res. 106, 95-104.

Frisina, R. D. (2001). Subcortical neural coding mechanisms for auditory temporal processing. Hear. Res. 158 , $1-27$.

Frisina, R. D. (2009). Age-related hearing loss: ear and brain mechanisms. Ann. N.Y. Acad. Sci. 1170, 708-717.

Frisina, R. D. (2010). "Aging changes in the central auditory system," in Handbook of Auditory Science: The Auditory Brain, eds A. Rees and A. Palmer (Oxford: Oxford University Press), 415-436.

Frisina, R. D., and Rajan, R. (2005) "Inferior colliculus: aging and plasticity," in The Inferior Colliculus, eds J. Winer and C. Schreiner (New York, NY: Springer), 559-584.

Frisina, R. D., and Walton, J. P. (2006). Age-related structural and functional changes in the cochlear nucleus. Hear. Res. 217, 216-233.

Frisina, R. D., Walton, J. P., LynchArmour, M. A., and Byrd, J. D. (1998). Inputs to a physiologicallycharacterized region of the inferior colliculus of the young adult CBA mouse. Hear. Res. 115, 61-81.

Fuentes-Santamaria, V., Alvarado, J. C., Brunso-Bechtold, J. K., and Henkel, C. K. (2003). Upregulation of calretinin immunostaining in the ferret inferior colliculus after cochlear ablation. J. Comp. Neurol. 460, 585-596.

Gates, G. A., and Mills, J. H. (2005). Presbycusis. Lancet 366, 1111-1120.

Gerken, G. M. (1996). Central tinnitus and lateral inhibition: an auditory brainstem model. Hear. Res. 97 , 75-83.

Geyer, M. A., and Braff, D. L. (1987), Startle habituation and sensorimotor gating in schizophrenia and related animal models. Schizophr. Bull. 13, 643-668.

Gonchar, Y., and Burkhalter, A. (1997). Three distinct families of
GABAergic neurons in rat visual cortex. Cereb. Cortex 7, 347-358.

Gonchar, Y., Wang, Q., and Burkhalter, A. (2007). Multiple distinct subtypes of GABAergic neurons in mouse visual cortex identified by triple immunostaining. Front. Neuroanat. 1:1-11. doi: 10.3389/neuro.05.003.2007

González-Hernández, T., Mantolan, B., González, B., and Pérez, H. (1996). Sources of GABAergic input to the inferior colliculus of the rat. J. Comp. Neurol. 372, 309-326.

Gordon-Salant, S., Fitzgibbons, P. J., and Friedman, S. A. (2007). Recognition of time-compressed and natural speech with selective temporal enhancements by young and elderly listeners. J. Speech Lang. Hear. Res. 50, 1181-1193.

Gordon-Salant, S., Frisina, R. D Popper, A., and Fay, R. R. (2010). The Aging Auditory System. New York, NY: Springer-Verlag.

Gutiérrez, A., Khan, Z. U., Morris, S. J., and De Blas, A. L. (1994). Agerelated decrease of GABAA receptor subunits and glutamic acid decarboxylase in the rat inferior colliculus. J. Neurosci. 14, 7469-7477.

Harker, K. T., and Whishaw, I. Q. (2002). Place and matching-toplace spatial learning affected by rat inbreeding (Dark-Agouti, Fischer 344) and albinism (Wistar, Sprague-Dawley) but not domestication (wild rat vs. Long-Evans, Fischer-Norway). Behav. Brain Res. 134, 467-477.

Helfert, R. H., Sommer, T. J., Meeks, J., Hofstetter, P., and Hughes, L. F. (1999). Age-related synaptic changes in the central nucleus of the inferior colliculus of Fischer-344 rats. J. Comp. Neurol. 406, 285-298.

Hendrickson, A. E., Tillakaratne, N. J., Mehra, R. D., Esclapez, M., Erickson, A., Vician, L., and Tobin, A. J. (1994). Differential localization of two glutamic acid decarboxylases (GAD65 and GAD67) in adult monkey visual cortex. J. Comp. Neurol. 343, 566-581.

Herculano-Houzel, S., and Lent, R. (2005). Isotropic fractionator: a simple, rapid method for the quantification of total cell and neuron numbers in the brain. J. Neurosci. $25,2518-2521$.

Hope, B. T., Michael, G. J., Knigge, K. M., and Vincent, S. R. (1991). Neuronal NADPH diaphorase is a nitric oxide synthase. Proc. Natl. Acad. Sci. U.S.A. 88, 2811-2814.

Idrizbegovic, E., Bogdanovic, N., Willott, J. F., and Canlon, B. (2004). Age-related increases in calciumbinding protein immunoreactivity 
in the cochlear nucleus of hearing impaired C57BL/6J mice. Neurobiol. Aging 25, 1085-1093.

Idrizbegovic, E., Canlon, B., Bross, L. S., Willott, J. F., and Bogdanovic, N. (2001). The total number of neurons and calcium binding protein positive neurons during aging in the cochlear nucleus of $\mathrm{CBA} / \mathrm{CaJ}$ mice: a quantitative study. Hear. Res. 158, 102-115.

Ito, T., Bishop, D. C., and Oliver, D. L. (2009). Two classes of GABAergic neurons in the inferior colliculus. J. Neurosci. 29, 13860-13869.

Jinno, S., and Kosaka, T. (2002). Patterns of expression of calcium binding proteins and neuronal nitric oxide synthase in different populations of hippocampal GABAergic neurons in mice. J. Comp. Neurol. 449, 1-25.

Jones, E. G. (2003). Chemically defined parallel pathways in the monkey auditory system. Ann. N.Y. Acad. Sci. 999, 218-233.

Kawaguchi, Y., and Kubota, Y. (1998). Neurochemical features and synaptic connections of large physiologically-identified GABAergic cells in the rat frontal cortex. Neuroscience 85, 677-701.

Kelley, P., Frisina, R. D., Zettel, M. L., and Walton, J. P. (1992). Differential calbindin immunoreactivity in the brainstem auditory system of the chinchilla. J. Comp. Neurol. 320, 196-212.

Khachaturian, Z. S. (1989). The role of calcium regulation in brain aging: re-examination of a hypothesis. Aging 1, 17-34.

Kirkcaldie, M. T., Dickson, T. C., King, C. E., Grasby, D., Riederer, B. M., and Vickers, J. C. (2002). Neurofilament triplet proteins are restricted to a subset of neurons in the rat neocortex. J. Chem. Neuroanat. 24, 163-171.

Koch, M. (1999). The neurobiology of startle. Prog. Neurobiol. 59, 107-128.

Krishna, B. S., and Semple, M. N. (2000). Auditory temporal processing: responses to sinusoidally amplitude-modulated tones in the inferior colliculus. J. Neurophysiol. $84,255-273$.

Kubota, Y., Hattori, R., and Yui, Y. (1994). Three distinct subpopulations of GABA-ergic neurons in rat frontal agranular cortex. Brain Res. 649, 159-173.

Kudo, M., and Nakamura, Y. (1988). "Organization of the lateral lemniscal fibers converging onto the inferior colliculus in the cat: an anatomical review," in Pathway: Structure and Function, eds J. Syka and R. B. Masterton (New
York, NY: Auditory Plenum Press), 171-183.

Kulesza, R. J. Jr., and Berrebi, A. S. (2000). Superior paraolivary nucleus of the rat is a GABAergic nucleus. J. Assoc. Res. Otolaryngol. 1, 255-269.

Kulesza, R. J., Viñuela, A., Saldaña, E., and Berrebi, A. S. (2002). Unbiased stereological estimates of neuron number in subcortical auditory nuclei of the rat. Hear. Res. 168, $12-24$.

Le Beau, F. E., Rees, A., and Malmierca, M. S. (1996). Contribution of GABA- and glycine-mediated inhibition to the monaural temporal response properties of neurons in the inferior colliculus. J. Neurophysiol. 75, 902-919.

Leventhal, A. G., Wang, Y., Pu, M., Zhou, Y., and Ma, Y. (2003). GABA and its agonists improved visual cortical function in senescent monkeys. Science 300, 812-815.

Ling, L. L., Hughes, L. F., and Caspary, D. M. (2005). Age-related loss of the GABA synthetic enzyme glutamic acid decarboxylase in rat primary auditory cortex. Neuroscience 132, 1103-1113.

Litovsky, R. Y., and Delgutte, B. (2002). Neural correlates of the precedence effect in the inferior colliculus: effect of localization cues. J. Neurophysiol. 87, 976-994.

Loftus, W. C., Malmierca, M. S., Bishop, D. C., and Oliver, D. L. (2008). The cytoarchitecture of the inferior colliculus revisited: a common organization of the lateral cortex in rat and cat. Neuroscience 154, 196-205.

Lohmann, C., and Friauf, E. (1996). Distribution of the calcium-binding proteins parvalbumin and calretinin in the auditory brainstem of adult and developing rats. J. Comp. Neurol. 367, 90-109.

Malmierca, M. S., Blackstad, T. W. and Osen, K. K. (2011). Computerassisted 3-D reconstructions of Golgi-impregnated neurons in the cortical regions of the inferior colliculus of rat. Hear. Res. 274 13-26.

Malmierca, M. S., Blackstad, T. W., Osen, K. K., Karagulle, T., and Molowny, R. L. (1993). The central nucleus of the inferior colliculus in rat: a Golgi and computer reconstruction study of neuronal and laminar structure. J. Comp. Neurol. $333,1-27$.

Malmierca, M. S., Hernandez, O. Falconi, A., Lopez-Poveda, E. A., Merchan, M., and Rees, A. (2003). The commissure of the inferior colliculus shapes frequency response areas in rat: an in vivo study using reversible blockade with microinjection of kynurenic acid. Exp. Brain Res. 153, 522-529.

Malmierca, M. S., Leergaard, T. B., Bajo, V. M., Bjaalie, J. G., and Merchan, M. A. (1998). Anatomic evidence of a three-dimensional mosaic pattern of tonotopic organization in the ventral complex of the lateral lemniscus in cat. J. Neurosci. 18 10603-10618.

Malmierca, M. S., Saint Marie, R. L., Merchan, M. A., and Oliver, D. L. (2005). Laminar inputs from dorsal cochlear nucleus and ventral cochlear nucleus to the central nucleus of the inferior colliculus: two patterns of convergence. Neuroscience 136, 883-894.

Malmierca, M. S., Seip, K. L., and Osen, K. K. (1995a). Morphological classification and identification of neurons in the inferior colliculus a multivariate analysis. Anat. Embryol. 191, 343-350.

Malmierca, M. S., Rees, A., Le Beau, F. E. N., and Bjaalie, J. G. (1995b). Laminar organization of frequencydefined local axons within and between the inferior colliculi of the guinea pig. J. Comp. Neurol. 357, 124-144.

Markram, H., Toledo-Rodriguez, M. Wang, Y., Gupta, A., Silberberg, G. and $\mathrm{Wu}, \mathrm{C}$. (2004). Interneurons of the neocortical inhibitory system. Nat. Rev. Neurosci. 5, 793-807.

Mattson, M. P. (2007). Calcium and neurodegeneration. Aging Cell 6 , 337-350.

Mazelová, J., Popelar, J., and Syka, J. (2003). Auditory function in presbycusis: peripheral vs. central changes. Exp. Gerontol. 38, 87-94.

Merchán, M., Aguilar, L. A., LopezPoveda, E. A., and Malmierca, M. S (2005). The inferior colliculus of the rat: quantitative immunocytochemical study of GABA and glycine. Neuroscience 136, 907-925.

Merrill, D. A., Chiba, A. A. and Tuszynski, M. H. (2001) Conservation of neuronal number and size in the entorhinal cortex of behaviorally characterized aged rats. J. Comp. Neurol. 438, 445-456.

Milbrandt, J. C., Albin, R. L., and Caspary, D. M. (1994). Age-related decrease in GABAB receptor binding in the Fischer 344 rat inferior colliculus. Neurobiol. Aging 15, 699-703.

Molnár, Z., and Cheung, A. F. (2006). Towards the classification of subpopulations of layer $\mathrm{V}$ pyramidal projection neurons. Neurosci. Res. $55,105-115$.

Morest, D. K., and Oliver, D. L. (1984). The neuronal architecture of the inferior colliculus of the cat: defining the functional anatomy of the auditory midbrain. J. Comp. Neurol. 222, 209-236.

Najdzion, J., Wasilewska, B., Równiak, M., Bogus-Nowakowska, K., Szteyn, S., and Robak, A. (2011). A morphometric comparative study of the medial geniculate body of the rabbit and the fox. Anat. Histol. Embryol. 40, 326-334.

Nataraj, K., and Wenstrup, J. J. (2005). Roles of inhibition in creating complex auditory responses in the inferior colliculus: facilitated combination-sensitive neurons. J. Neurophysiol. 93, 3294-3312.

Nodal, F. R., and López, D. E. (2003). Direct input from cochlear root neurons to pontine reticulospinal neurons in albino rat. J. Comp. Neurol. 460, 80-93.

Ohlemiller, K. K., and Frisina, R. D. (2008). "Clinical characterization of age-related hearing loss and its neural and molecular bases," in Auditory Trauma, Protection and Treatment, eds J. Schacht, A. Popper, and R. Fay (New York, NY: SpringerVerlag), 145-194.

Oliver, D. L. (1984). Neuron types in the central nucleus of the inferior colliculus that project to the medial geniculate body. Neuroscience 11, 409-424.

Oliver, D. L., and Huerta, M. F. (1992). "Inferior and superior colliculi," in The Mammalian Auditory System: Neuroanatomy, eds D. B. Webster, A. N. Popper, and R. R. Fay (New York, NY: Springer-Verlag), 168-221.

Oliver, D. L., Kuwada, S., Yin, T. C., Haberly, L. B., and Henkel, C. K. (1991). Dendritic and axonal morphology of HRP-injected neurons in the inferior colliculus of the cat. J. Comp. Neurol. 303, 75-100.

Oliver, D. L., and Morest, D. K. (1984). The central nucleus of the inferior colliculus in the cat. J. Comp. Neurol. 222, 237-264.

Oliver, D. L., Winer, J. A., Beckius, G. E., and Saint Marie, R. L. (1994). Morphology of GABAergic neurons in the inferior colliculus of the cat. J. Comp. Neurol. 340, 27-42.

Ouda, L., Druga, R., and Syka, J. (2008). Changes in parvalbumin immunoreactivity with aging in the central auditory system of the rat. Exp. Gerontol. 43, 782-789.

Ouda, L., Druga, R., and Syka, J. (2012a). Distribution of SMI-32immunoreactive neurons in the central auditory system of the rat. Brain Struct. Funct. 217, 19-36.

Ouda, L., Burianova, J., and Syka, J. (2012b). Age-related changes in calbindin and calretinin 
immunoreactivity in the central auditory system of the rat. Exp. Geront. 47, 497-506.

Pakkenberg, B., and Gundersen, H. J. (1997). Neocortical neuron number in humans: effect of sex and age. J. Comp. Neurol. 384, 312-320.

Palombi, P. S., and Caspary, D. M. (1996). Physiology of the aged Fischer 344 rat inferior colliculus: responses to contralateral monaural stimuli. J. Neurophysiol. 76, 3114-3125.

Paxinos, G., and Watson, C. (1998). The Rat Brain in Stereotaxic Coordinates. New York, NY: Academic Press.

Pecka, M., Zahn, T. P., Saunier-Rebori, B., Siveke, I., Felmy, F., Wiegrebe, L., Klug, A., Pollak, G. D., and Grothe, B. (2007). Inhibiting the inhibition: a neuronal network for sound localization in reverberant environments. J. Neurosci. 27, 1782-1790.

Peruzzi, D., Bartlett, E., Smith, P. H., and Oliver, D. L. (1997). A monosynaptic GABAergic input from the inferior colliculus to the medial geniculate body in rat. J. Neurosci. 17, 3766-3777.

Poe, B. H., Linville, C., and BrunsoBechtold, J. (2001). Age-related decline of presumptive inhibitory synapses in the sensorimotor cortex as revealed by the physical disector. J. Comp. Neurol. 406, 285-298.

Pollak, G. D., and Casseday, J. H. (1986). The Neural Basis of Echolocation in Bats. New York, NY: Springer-Verlag.

Pollak, G. D., Xie, R., Gittelman, J. X., Andoni, S., and Li, N. (2011). The dominance of inhibition in the inferior colliculus. Hear. Res. 274, 27-39.

Popelar, J., Groh, D., Mazelova, J., and Syka, J. (2003). Cochlear function in young and adult Fischer 344 rats. Hear. Res. 186, 75-84.

Popelar, J., Groh, D., Pelanova, J., Canlon, B., and Syka, J. (2006). Age-related changes in cochlear and brainstem auditory functions in Fischer 344 rats. Neurobiol. Aging 27, 490-500.

Raza, A., Milbrandt, J. C., Arneric, S. P., and Caspary, D. M. (1994). Agerelated changes in brainstem auditory neurotransmitters: measures of GABA and acetylcholine function. Hear. Res. 77, 221-230.

Résibois, A., and Rogers, J. H. (1992). Calretinin in rat brain: an immunohistochemical study. Neuroscience 46, 101-134.

Riascos, D., De Leon, D., Baker-Nigh, A., Nicholas, A., Yukhananov, R., Bu, J., Wu, C. K., and Geula, C. (2011). Age-related loss of calcium buffering and selective neuronal vulnerability in Alzheimer's disease. Acta Neuropathol. 122, 565-576.

Riquelme, R., Saldana, E., Osen, K. K., Ottersen, O. P., and Merchan, M. A. (2001). Colocalization of GABA and glycine in the ventral nucleus of the lateral lemniscus in rat: an in situ hybridization and semiquantitative immunocytochemical study. J. Comp. Neurol. 432, 409-424.

Rybalko, N., Bureš, Z., Burianová, J., Popelár, J., Poon, P. W. F., and Syka, J. (in press). Age-related changes in the acoustic startle reflex in Fischer 344 and Long Evans rats. Exp. Geront.

Rybalko, N., Suta, D., Popelár, J., and Syka, J. (2010). Inactivation of the left auditory cortex impairs temporal discrimination in the rat. Behav. Brain Res. 209, 123-130.

Saint Marie, R. L., and Baker, R. A. (1990). Neurotransmitter-specific uptake and retrograde transport of $[3 \mathrm{H}]$ glycine from the inferior colliculus by ipsilateral projections of the superior olivary complex and nuclei of the lateral lemniscus. Brain Res. 524, 244-253.

Saint Marie, R. L., Ostapoff, E. M., Morest, D. K., and Wenthold, R. J. (1989). Glycine-immunoreactive projection of the cat lateral superior olive: possible role in midbrain ear dominance. J. Comp. Neurol. 279, 382-396.

Saldaña, E., Aparicio, M. A., FuentesSantamaría, V., and Berrebi, A. S. (2009). Connections of the superior paraolivary nucleus of the rat: projections to the inferior colliculus. Neuroscience 163, 372-387.

Saldana, E., Feliciano, M., and Mugnaini, E. (1996). Distribution of descending projections from primary auditory neocortex to inferior colliculus mimics the topography of intracollicular projections. J. Comp. Neurol. 371, 15-40.

Sanchez, J. T., Gans, D., and Wenstrup, J. J. (2007). Contribution of NMDA and AMPA receptors to temporal patterning of auditory responses in the inferior colliculus. J. Neurosci. 27, 1954-1963.

Schmidt, S., Redecker, C., Bruehl, C., and Witte, O. W. (2010). Agerelated decline of functional inhibition in rat cortex. Neurobiol. Aging 31, 504-511.

Schneiderman, A., Oliver, D. L., and Henkel, C. K. (1988). Connections of the dorsal nucleus of the lateral lemniscus: an inhibitory parallel pathway in the ascending auditory system? J. Comp. Neurol. 276, 188-208.
Schofield, B. R. (2009). Projections to the inferior colliculus from layer VI cells of auditory cortex. Neuroscience 159, 246-258.

Schwaller, B. (2010). Cytosolic Ca2+ buffers. Cold Spring Harb. Perspect. Biol. 2, a004051

Schwaller, B., Meyer, M., and Schiffmann, S. (2002). 'New' functions for 'old' proteins: the role of the calcium-binding proteins calbindin D-28k, calretinin and parvalbumin, in cerebellar physiology. Studies with knockout mice. Cerebellum 1, 241-258.

Semple, M. N., and Aitkin, L. M. (1980). Physiology of pathway from dorsal cochlear nucleus to inferior colliculus revealed by electrical and auditory stimulation. Exp. Brain Res. 41, 19-28.

Sharma, V., Nag, T. C., Wadhwa, S. and Roy, T. S. (2009). Stereological investigation and expression of calcium-binding proteins in developing human inferior colliculus. J. Chem. Neuroanat. 37, 78-86.

Sheikh, S. N., Martin, S. B., and Martin, D. L. (1999). Regional distribution and relative amounts of glutamate decarboxylase isoforms in rat and mouse brain. Neurochem. Int. 35 , 73-80.

Shi, L., Argenta, A. E., Winseck, A K., and Brunso-Bechtold, J. K. (2004). Stereological quantification of GAD-67-immunoreactive neurons and boutons in the hippocampus of middle-aged and old Fischer 344 x Brown Norway rats. J. Comp. Neurol. 478, 282-291.

Shi, L., Pang, H., Linville, M. C., Bartley, A. N., Argenta, A. E. and Brunso-Bechtold, J. K. (2006). Maintenance of inhibitory interneurons and boutons in sensorimotor cortex between middle and old age in Fischer $344 \mathrm{X}$ Brown Norway rats. J. Chem. Neuroanat. 32, 46-53.

Simon, H., Frisina, R. D., and Walton, J. P. (2004). Age reduces response latency of mouse inferior colliculus neurons to AM sounds. J. Acoust. Soc. Am. 116, 469-477.

Stanley, D. P., and Shetty, A. K. (2004). Aging in the rat hippocampus is associated with widespread reductions in the number of glutamate decarboxylase-67 positive interneurons but not interneuron degeneration. J. Neurochem. 89, 204-216.

Sternberger, L. A., and Sternberger, N. H. (1983). Monoclonal antibodies distinguish phosphorylated and nonphosphorylated forms of neurofilaments in situ. Proc. Natl. Acad. Sci. U.S.A. 80, 6126-6130.
Strouse, A., Ashmead, D. H., Ohde, R. N., and Grantham, D. W. (1998). Temporal processing in the aging auditory system. J. Acoust. Soc. Am. 104, 2385-2399.

Suta, D., Kvasnák, E., Popelár, J., and Syka, J. (2003). Representation of species-specific vocalizations in the inferior colliculus of the guinea pig. J. Neurophysiol. 90, 3794-3808.

Suta, D., Rybalko, N., Pelánová, J., Popelár, J., and Syka, J. (2011). Agerelated changes in auditory temporal processing in the rat. Exp. Gerontol. 46, 739-746.

Swerdlow, N. R., Geyer, M. A., and Braff, D. L. (2001). Neural circuit regulation of prepulse inhibition of startle in the rat: current knowledge and future challenges. Psychopharmacology 156, 194-215.

Syka, J. (2002). Plastic changes in the central auditory system after hearing loss, restoration of function, and during learning. Physiol. Rev. 82, 601-636.

Syka, J. (2010). The Fischer 344 rat as a model of presbycusis. Hear. Res. 264, 70-78.

Syka, J., and Radil-Weiss, T. (1971). Electrical stimulation of the tectum in freely moving cats. Brain Res. 28, 567-572.

Syka, J., and Straschill, M. (1970). Activation of superior colliculus neurons and motor responses after electrical stimulation of the inferior colliculus. Exp. Neurol. 28, 384-392.

Tardif, E., Chiry, O., Probst, A., Magistretti, P. J., and Clarke, S. (2003). Patterns of calcium-binding proteins in human inferior colliculus: identification of subdivisions and evidence for putative parallel systems. Neuroscience 116, 1111-1121.

Toescu, E. C., Verkhratsky, A., and Landfield, P. W. (2004). Ca2+ regulation and gene expression in normal brain aging. Trends Neurosci. 27, 614-620.

Tokunaga, A., Sugita, S., and Otani, K. (1984). Auditory and non-auditory subcortical afferents to the inferior colliculus in the rat. J. Hirnforsch. 25, 461-472.

Tsang, Y. M., Chiong, F., Kuznetsov, D., Kasarskis, E., and Geula, C. (2000). Motor neurons are rich in non-phosphorylated neurofilaments: crossspecies comparison and alterations in ALS. Brain Res. 861, 45-58.

Verkhratsky, A., and Toescu, E. C. (1998). Calcium and neuronal ageing. Trends Neurosci. 21, 2-7. 
Voelker, C. C., Garin, N., Taylor, J. S., Gähwiler, B. H., Hornung, J. P., and Molnár, Z. (2004). Selective neurofilament (SMI-32, FNP-7 and N200) expression in subpopulations of layer $\mathrm{V}$ pyramidal neurons in vivo and in vitro. Cereb. Cortex 14, 1276-1286.

Walton, J. P. (2010). Timing is everything: temporal processing deficits in the aged auditory brainstem. Hear. Res. 264, 63-69.

Walton, J. P., Barsz, K., and Wilson, W. W. (2008). Sensorineural hearing loss and neural correlates of temporal acuity in the inferior colliculus of the $\mathrm{C} 57 \mathrm{Bl} / 6$ mouse. J. Assoc. Res. Otolaryngol. 9, $12-22$.

Walton, J. P., Frisina, R. D., and O'Neill, W. E. (1998). Age-related alteration in processing of temporal sound features in the auditory midbrain of the CBA mouse. J. Neurosci. 18, 2764-2776.

Walton, J. P., Frisina, R. D., Ison, J. E., and O'Neill, W. E. (1997). Neural correlates of behavioral gap detection in the inferior colliculus of the young CBA mouse. J. Comp. Physiol. A 181, Wu, M. D., Kimura, M., Hiromichi, 161-176.

Walton, J. P., Simon, H., and Frisina, R. D. (2002). Age-related alterations in the neural coding of envelope periodicities. J. Neurophysiol. 88, 565-578.

Winer, J. A., and Larue, D. T. (1996). Evolution of GABAergic circuitry in the mammalian medial geniculate body. Proc. Natl. Acad. Sci. U.S.A. 93, 3083-3087.

Winer, J. A., Larue, D. T., and Pollak, G. D. (1995). GABA and glycine in the central auditory system of the mustache bat: structural substrates for inhibitory neural organization. J. Comp. Neurol. $352,1-37$.

Winer, J. A., Larue, D. T., Diehl, J. J., and Hefti, B. J. (1998). Auditory cortical projections to the cat inferior colliculus. J. Comp. Neurol. 400, 147-174.

Woo, N. H., and Lu, B. (2006). Regulation of cortical interneurons by neurotrophins: from development to cognitive disorders. Neuroscientist 12, 43-56.

classification of NOergic neurons in the inferior colliculus of rat according to co-existence with classical amino acid transmitters. Okajimas Folia Anat. Jpn. 85, 17-27.

Zettel, M. L., Frisina, R. D., Haider, S. E., and O'Neill, W. E. (1997). Agerelated changes in calbindin D-28k and calretinin immunoreactivity in the inferior colliculus of $\mathrm{CBA} / \mathrm{CaJ}$ and C57Bl/6 mice. J. Comp. Neurol. 386, 92-110.

Zettel, M. L., O'Neill, W. E., Trang, T. T., and Frisina, R. D. (2001). Early bilateral deafening prevents calretinin up-regulation in the dorsal cortex of the inferior colliculus of aged CBA/CaJ mice. Hear. Res. 158, 131-138.

Zhang, D. X., Li, L., Kelly, J. B., and Wu, S. H. (1998). GABAergic projections from the lateral lemniscus to the inferior colliculus of the rat. Hear. Res. 117, 1-12.

Zhou, J., and Shore, S. (2006). Convergence of spinal trigeminal and cochlear nucleus projections in the inferior colliculus of the guinea pig. J. Comp. Neurol. 495, 100-112.
Conflict of Interest Statement: The authors declare that the research was conducted in the absence of any commercial or financial relationships that could be construed as a potential conflict of interest.

Received: 18 June 2012; accepted: 04 September 2012; published online: 21 September 2012.

Citation: Ouda L and Syka J (2012)

Immunocytochemical profiles of inferior colliculus neurons in the rat and their changes with aging. Front. Neural Circuits 6:68. doi: 10.3389/fncir. 2012.00068

Copyright (C) 2012 Ouda and Syka. This is an open-access article distributed under the terms of the Creative Commons Attribution License, which permits use, distribution and reproduction in other forums, provided the original authors and source are credited and subject to any copyright notices concerning any third-party graphics etc. 